\title{
Functional Dissection of Polycomb Repressive Complex 1 Reveals the Importance of a Charged Domain
}

\author{
D.J. GRAU, ${ }^{1,2,4}$ J.M. ANTAO, ${ }^{1-4}$ AND R.E. Kingston ${ }^{1,2}$ \\ ${ }^{1}$ Department of Molecular Biology, Massachusetts General Hospital, Boston, Massachusetts 02114; \\ ${ }^{2}$ Department of Genetics, Harvard Medical School, Boston, Massachusetts 02115; ${ }^{3}$ Gulbenkian \\ PhD Program in Biomedicine, Instituto Gulbenkian de Ciência (IGC), Oeiras, Portugal \\ Correspondence: Kingston@molbio.mgh.harvard.edu
}

\begin{abstract}
Silencing of homeotic genes requires the Polycomb repressive complex 1 (PRC1) family of protein complexes, which are composed of Polycomb-group (PcG) proteins and frequently include other subunits. We discuss here two aspects of PRC1 that might contribute to this activity. Inhibiting the action of remodeling factors via chromatin compaction is believed to be one mechanism by which PRC1 represses genes. We show that PRC1s from fly and mouse have conserved this activity as complexes. Additionally, we provide evidence that a different subunit in the mouse complex retains the conserved repression activity and that activity appears to be mediated by charge interactions. We show that Zeste interacts specifically with the Ph subunit of PRC1 and discuss the possibility of these factors contributing to spreading of PRC1 complexes. Our results suggest that one aspect of PRC1 repression is likely to be mediated by charge-charge interactions.
\end{abstract}

A key aspect of development is the ability to maintain master regulatory genes in a repressed state when appropriate. Misexpression of even a single master regulatory gene, such as those encoded in the HOX loci, can cause a cell to behave in a manner incompatible with its body location and tissue type. The most prominent set of factors responsible for the maintenance of a repressed state at master regulatory genes is called the Polycomb group $(\mathrm{PcG})$, after the founding gene in this family, Polycomb, discovered in Drosophila in the late 1940s (Lewis 1947; Lewis 1978). The PcG genes, which number roughly 16 depending on species, form several protein complexes that are involved in repression. One of these complexes, Polycomb repressive complex 1 (PRC1), is believed to be the central engine of repression.

The mechanisms via which the PcG system maintains a repressed state faithfully throughout the lifetime of a cell lineage are not fully understood. The system is targeted to genes by specific loci called Polycomb response elements (PREs). Several distinct DNA-binding factors bind to PREs, localize PcG complexes via interactions with these complexes, and allow these complexes to act at adjacent, and many times distant $(>50 \mathrm{~kb})$, regions of the genome (for review, see Ringrose and Paro 2007). More recently, there have been some suggestions that noncoding RNAs (ncRNAs) are also involved in targeting (Rinn et al. 2007; Zhao et al. 2008). Once the targets are found, repression involves methylation of lysine 27 of histone H3, ubiquitylation of lysine 119 of histone H2A, binding to and stabilization of nucleosome structure, and direct inhibition of the transcription machinery (for review, see Simon and

${ }^{4}$ These authors contributed equally to this work.
Kingston 2009). Given the number of PcG components, the variety of genes that are regulated, and the fact that key targets such as the HOX clusters occupy $\sim 500 \mathrm{~kb}$ in the mammalian and in the Drosophila genomes, it seems likely that a variety of mechanisms act in distinct combinations on the various targets.

Several complexes are formed by $\mathrm{PcG}$ gene products. In Drosophila, these include PRC1 (Shao et al. 1999; Saurin et al. 2001), PRC2 (Czermin et al. 2002; Kuzmichev et al. 2002; Müller et al. 2002), PhoRC (Klymenko et al. 2006), and PR-DUB (Scheuermann et al. 2010). PhoRC binds to many PREs to help target the repressive PcG machinery; PRC2 methylates lysine 27 of histone $\mathrm{H} 3$ to help target binding by the PRC1 complex, which creates a repressive state on chromatin; and PR-DUB deubiquitylates histone $\mathrm{H} 2 \mathrm{~A}$, thus counteracting one of the functions of the PRC1 family of complexes. The extent to which this balance of counteracting PcG activities drives a repressive state is not understood currently. It is also not clear whether PRC2 is involved only in targeting PRC1 or whether it directly represses gene expression in coordination with PRC1 as well.

PRC1 family members have been found in complexes distinct from PRC1 as originally defined in Drosophila (Table 1). These complexes also have tight interactions with proteins that do not display a classic PcG phenotype and thus are not bona fide PcG members. Complexes in this family have several functions. Complexes that contain the Bmi-1 and Ring1B proteins are able to ubiquitylate histone $\mathrm{H} 2 \mathrm{~A}$; the most active of these complexes also contain the KDM2B protein or its homolog (Gearhart et al. 2006; Lagarou et al. 2008). The role for ubiquitylation in directing repression is under investigation; it has been proposed to impede transcriptional elongation (Stock et al. 2007) but does not appear key for repression of HOX loci in mice 
Table 1. Selected PcG proteins

\begin{tabular}{|c|c|c|c|c|}
\hline Drosophila & Mouse & Complex & Domains & Functional role(s) \\
\hline Enhancer of zeste (E(sz)) & $\begin{array}{l}\text { Ezh1P } \\
\text { Ezh2 (KMT6, Enx-1) }\end{array}$ & $\begin{array}{l}\mathrm{PRC} 2 \\
\mathrm{PRC} 2\end{array}$ & $\begin{array}{l}\text { SET } \\
\text { SET }\end{array}$ & H3K27 Mouse \\
\hline Suppressor zeste $12(\mathrm{Su}(\mathrm{z}) 12)$ & Suz12 & PRC2 & & Enhances Mtase activity of E(z) \\
\hline Extra sex combs (Esc) & Eed (lusk) & PRC2 & WD40 repeats & Enhances Mtase activity of E(z) \\
\hline $\begin{array}{l}\text { Nucleosome remodeling } \\
\text { factor } 55 \text { (Nurf55/Caf-1) }\end{array}$ & Rbbp4 (Caf-1, mRbAp48) & PRC2 & WD40 repeats & Nucleosome binding \\
\hline Polycomb-like (Pcl) & $\begin{array}{l}\text { Phf1 (Pcd1) } \\
\text { Mtf2 (Pcl2) } \\
\text { Phf19 (Pcl3) }\end{array}$ & $\begin{array}{l}\text { Interacts } \\
\text { with PRC2 }\end{array}$ & $\begin{array}{l}\text { PHD fingers and } \\
\text { Tudor domain }\end{array}$ & $\begin{array}{l}\text { Recruitment, enhances Mtase } \\
\text { activity of PRC } 2\end{array}$ \\
\hline \multirow[t]{5}{*}{ Polycomb (Pc) } & Cbx2 (M33, MOD2, Pc1) & $\mathrm{PRC} 1$ & $\begin{array}{l}\text { Chromodomain } \\
\text { AT-hook and } \\
\text { Pc-box }\end{array}$ & Binds H3K27triMe \\
\hline & $\mathrm{Cbx} 4(\mathrm{Pc} 2)$ & PRC1 & $\begin{array}{l}\text { Chromodomain } \\
\text { and Pc-box }\end{array}$ & Binds H3K27triMe \\
\hline & Cbx6 & PRC1 & $\begin{array}{l}\text { Chromodomain } \\
\text { and Pc-box }\end{array}$ & Binds H3K27triMe \\
\hline & $\mathrm{Cbx} 7$ & PRC1 & $\begin{array}{l}\text { Chromodomain } \\
\text { and Pc-box }\end{array}$ & Binds H3K27triMe \\
\hline & $\mathrm{Cbx} 8(\mathrm{Pc} 3)$ & PRC1 & $\begin{array}{l}\text { Chromodomain } \\
\text { and Pc-box }\end{array}$ & Binds H3K27triMe \\
\hline $\begin{array}{l}\text { Posterior sex combs (Psc) and } \\
\text { Suppressor of zeste } 2 \\
(\mathrm{Su}(\mathrm{z}) 2)\end{array}$ & $\begin{array}{l}\text { Bmi1 (Pcgf4) } \\
\text { Mel18 (Pcgf2, Rnf110) } \\
\text { Pcgf1 (Nspc1) }\end{array}$ & $\begin{array}{l}\text { PRC1 } \\
\text { PRC1 } \\
\text { BCOR }\end{array}$ & $\begin{array}{l}\text { RING finger } \\
\text { RING finger } \\
\text { RING finger }\end{array}$ & $\begin{array}{l}\text { Enhances ubiquitination } \\
\text { Compacts nucleosomes }\end{array}$ \\
\hline $\begin{array}{l}\text { Polyhomeotic proximal (Ph-p) } \\
\text { and distal (Ph-d) }\end{array}$ & $\begin{array}{l}\text { Phc1 (Edr, Mph1, Rae-28) } \\
\text { Phc2 (Edr2, Mphj2, p36) } \\
\text { Phc3 (Edr3, Hph3) }\end{array}$ & $\begin{array}{l}\text { PRC1 } \\
\text { PRC1 } \\
\text { PRC1 }\end{array}$ & $\begin{array}{l}\text { SAM } \\
\text { SAM } \\
\text { SAM }\end{array}$ & $\begin{array}{l}\text { Spreading? } \\
\text { Spreading? } \\
\text { Spreading? }\end{array}$ \\
\hline Sex combs extra (Sce/dRing) & $\begin{array}{l}\text { Ring1 (Ring1A) } \\
\text { Rnf2 (Ring1B, dinG) }\end{array}$ & $\begin{array}{l}\text { PRC1/BCOR } \\
\text { PRC1/BCOR }\end{array}$ & $\begin{array}{l}\text { RING finger } \\
\text { RING finger }\end{array}$ & $\begin{array}{l}\text { E3 ligase } \\
\text { E3 ligase }\end{array}$ \\
\hline Pleiohomeotic (Pho) & YY1 (NF-E1) & PhoRC & Zn fingers & Recruitment? \\
\hline dSfmbt & mSfmbt (Smr) & PhoRC & $\begin{array}{l}\text { Zn finger, MBT, } \\
\text { and SAM }\end{array}$ & Binds methylated histones \\
\hline Calypso & Bap1 & PR-DUB & $\mathrm{UCH}$ & Deubiquitinates H2A \\
\hline Additional sex combs (Asx) & $\begin{array}{l}\text { Asxl1 } \\
\text { Bcor }\end{array}$ & $\begin{array}{l}\text { PR-DUB } \\
\text { BCOR }\end{array}$ & Ankyrin repeat & $\begin{array}{l}\text { Enhances Calypso activity } \\
\text { Targeting H2A ubiquitination? }\end{array}$ \\
\hline dKDM2 & $\mathrm{Kdm} 2 \mathrm{~b}(\mathrm{Fbx} 110)$ & $\mathrm{BCOR}$ & $\begin{array}{l}\text { CXXC, PHD } \\
\text { finger, F-box, } \\
\text { and leucine- } \\
\text { rich repeats }\end{array}$ & H3K36 demethylase \\
\hline dRYBP & Rybp (DEDAF, YEAF1) & BCOR & Zn finger & Protein-protein interaction \\
\hline skpA & $\begin{array}{l}\text { Skp1a (EMC19, OCP2, } \\
\text { SKP1A, p19A) }\end{array}$ & $\mathrm{BCOR}$ & SKP1 & \\
\hline
\end{tabular}

(Eskeland et al. 2010). It is possible that the importance of ubiquitylation varies according to the repressed target gene. A second activity of the PRC1 family complexes, and a focus of this chapter, is their ability to create a compacted chromatin state that is refractory to ATP-dependent remodeling. Creation of a compacted state has been proposed to direct repression by blocking steps in the transcription process (Nakagawa et al. 2008), possibly at the level of transcription initiation or transcription elongation. A second focus of this chapter is the ability of auxiliary factors to modulate activity and/or targeting of PRC1 activities.

To dissect the mechanism of PRC1 function, we have analyzed domains of some of its central components. In previous work, we showed that the Psc protein is responsible for creating a compacted state of the template (Francis et al. 2001) and defined the regions of Psc responsible for that activity (King et al. 2005). An issue that arose was that there was no obvious homologous domain in mammalian Psc homologs: If this activity is central to PRC1 function, where might a domain reside that performs this activity in mammals? In previous work, we had also shown that a key protein involved in both activation and repression in Drosophila, the Zeste protein, interacts directly with the core components of PRC1 (Saurin et al. 2001; Mulholland et al. 2003). This was perplexing because, although this protein is known to have roles in regulation in Drosophila, it has been shown to display phenotypes consistent with the Trithorax group (Judd 1995), a set of genes isolated by their ability to suppress PcG phenotypes. We have addressed the ability of Zeste to dock with PRC1 and tested whether there are functional outcomes from this interaction. 


\section{MATERIALS AND METHODS}

\section{Protein Expression}

Protein expression was performed as described previously (Phelan et al. 1999). Briefly, Sf9 cells in the exponential growth phase were infected with baculovirus for the desired proteins, and cells were harvested $40 \mathrm{~h}$ after infection. Nuclear extracts were prepared as described (Abmayr et al. 2001), and protein was bound to an M2 affinity resin (Sigma), washed with BC buffer (20 mM HEPES at pH 8.0, 0.2 mM EDTA, 20\% glycerol, 0.2 mM PMSF, $0.5 \mathrm{~mm} \mathrm{DTT}$ ), with $\mathrm{KCl}$ concentrations up to $2 \mathrm{M}$, and eluted with $0.4 \mathrm{mg} / \mathrm{mL}$ Flag peptide.

\section{Protein-Protein Interaction Assays}

Sf9 cells at a density of $5 \times 10^{5} / \mathrm{mL}$ were coinfected with baculovirus for the candidate interacting proteins. Cells were harvested after $40 \mathrm{~h}$ and washed with PBS, and cell extracts were prepared by freezing/thawing three times in the presence of protease inhibitors. Extracts were incubated with $\mathrm{M} 2$ beads, washed with $\mathrm{BC}$ buffer with $\mathrm{KCl}$ concentrations up to $2 \mathrm{M}$, and eluted with $0.4 \mathrm{mg} / \mathrm{mL}$ Flag peptide. Proteins were separated by SDS-PAGE and detected either by Western blot or Colloidal Blue staining (Invitrogen).

\section{Generation of Nucleosomal Arrays}

The ClaI/Asp118 fragment of pG5E4 containing 10 5S nucleosome positioning sequences was purified using standard molecular biology techniques. Purified G5E4 fragment was end-labeled using Klenow and $\left[\alpha_{-}{ }^{32} \mathrm{P}\right] \mathrm{dATP}$. Core nucleosomes were prepared from HeLa nuclei and assembled into nucleosomal arrays using the salt gradient dialysis method as previously described (Sif et al. 2001).

\section{Restriction Enzyme Accessibility Assay}

The restriction enzyme accessibility assay was performed essentially as described (Francis et al. 2001). Briefly, 1.5 nM nucleosomes was incubated with PcG proteins at the indicated concentration for $30 \mathrm{~min}$ at $30^{\circ} \mathrm{C}$. Afterward, $\mathrm{hSWI} / \mathrm{SNF}$ was added at concentrations determined not to be rate-limiting, in the presence of 8 units of HhaI (New England BioLabs) in $20 \mu \mathrm{L}$ of reaction buffer containing 12 mM HEPES (pH 7.9), 0.2 nM EDTA, 1.5 mM MgCl 2.4 $\mu \mathrm{g}$ of BSA, $5 \%$ glycerol, $2 \mathrm{~mm}$ ATP, and $1 \mathrm{~mm}$ DTT. After an additional $1 \mathrm{~h}$ at $30^{\circ} \mathrm{C}$, the $20-\mu \mathrm{L}$ reactions were quenched by the addition of $10 \mu \mathrm{L}$ of stop buffer: $10 \mathrm{mM}$ Tris (pH 7.7), 35 mm EDTA, 1\% SDS, $0.1 \mathrm{mg} / \mathrm{mL}$ bromophenol blue, and $1.5 \mathrm{mg} / \mathrm{mL}$ Proteinase K. Stopped reactions were incubated for $45 \mathrm{~min}$ at $55^{\circ} \mathrm{C}$, then resolved on a $1 \%$ agarose gel before exposure to a phospho-imaging screen and quantification using a Typhoon PhosphorImager and ImageQuant software (GE Healthcare).

\section{Evolutionary Analysis}

The UniProt database was queried for proteins containing either chromodomains or RING domains. These lists of proteins were further filtered by removing proteins that did not contain a C-box in the chromodomain list or did not contain the extra region of homology in the RING protein set. The proteins in these lists were classified as active or inactive based on predicted overall charge, with +10.2 being the cutoff point, with proteins more positively charged being classified as active. The cladogram was generated by aligning the $18 \mathrm{~S}$ rRNA sequences for each of the listed organisms, and the cladogram was drawn using the neighbor-joining method using NJplot.

\section{RESULTS}

\section{Chromatin Compaction Is Conserved in the Mouse PRC1 Complex}

The domains responsible for chromatin compaction by Drosophila PRC1 were shown by solution studies and by electron microscopy to reside in the carboxy-terminal twothirds of the Psc protein (Francis et al. 2004; King et al. 2005). Function is dispersed in a large region of the protein, and there is a good correlation between how mutations in Psc affect the in vivo phenotype and how those mutations affect compaction by Psc in vitro. Bmil, one of the mouse homologs of Psc, is structurally quite different from Psc. Although Bmil and Psc share a conserved RING finger and HTH domain, Bmil lacks the extended carboxyterminal region of Psc that is required for both in vitro and in vivo function. Thus, we were interested in whether Bmi1 or another mouse PRC1 protein was capable of functioning in isolation in vitro in a manner similar to Psc.

We expressed and purified individual components of mouse Polycomb core complex (mPCC) and tested them for the ability to inhibit remodeling in a solution protocol based on restriction enzyme accessibility. Restriction enzyme cleavage is inhibited when the target DNA is organized into a nucleosome. ATP-dependent remodeling proteins modify the nucleosomal structure in ways that allow accessibility and cleavage, but in the presence of PRC1, this activity is blocked. We measure the ability of a PRC1 preparation to function by titrating it into a remodeling reaction and measuring the extent to which restriction enzyme access is inhibited. This function has generally correlated well with the ability to compact chromatin, as studied using electron microscopy (Francis et al. 2004). Using this protocol, a reconstituted complex containing proteins Bmi1, M33/Cbx2, and Ring1a showed activity similar to that seen with Drosophila Psc (Fig. 1).

We tested individual mouse PcG proteins to determine whether any single protein is able to inhibit remodeling. Bmil does not significantly inhibit remodeling at the concentrations of protein tested (Fig. 1), consistent with the fact that it does not contain a region homologous to the compaction domain defined in Psc. Next, we tested the other components of the minimal core complex for repression activity. Similar to Bmi1, Ring1a does not show any appreciable activity on its own. However, M33/Cbx2 inhibits remodeling to an extent similar to the mouse core complex and Psc. This is surprising because we had previously observed little in vitro activity of the Drosophila homolog of M33/Cbx2, Pc. 
A
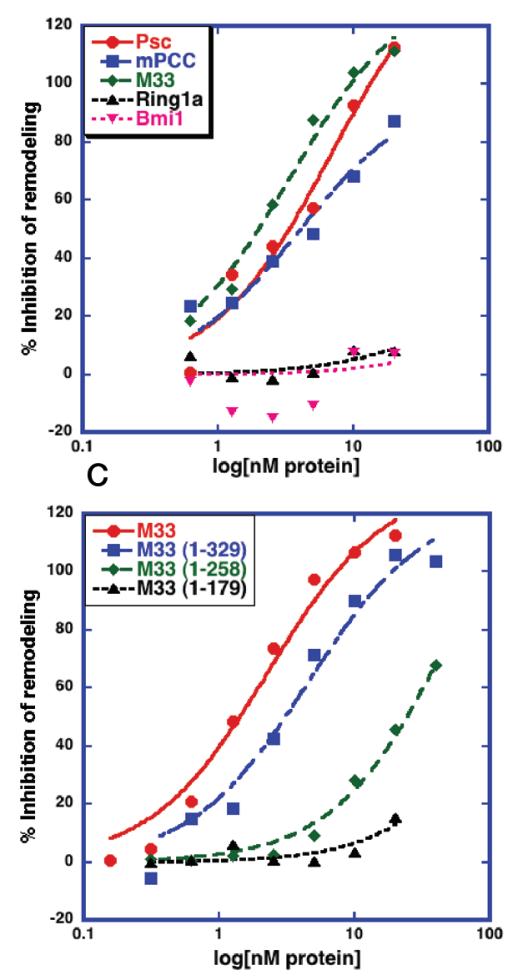

B
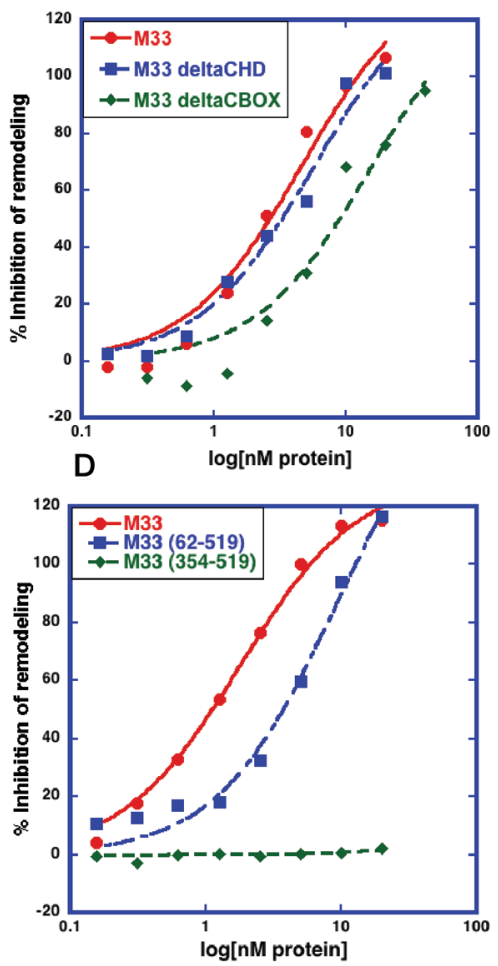

Figure 1. Repressive activity of PcG protein M33. PcG proteins were titrated into a reaction containing nucleosomal arrays and incubated before addition of hSWI/SNF and Hhal. Remodeling is measured by quantifying the ratio of DNA cut by HhaI to uncut DNA. The percent inhibition of remodeling is calculated by using the following equation:

$$
\frac{(\% \text { uncut with hSWI/SNF and PRC1 or PCC }-\% \text { uncut with hSWI/SNF })}{(\% \text { uncut without hSWI/SNF }-\% \text { uncut with hSWI/SNF })} \times 100 .
$$

(A) The ability of M33 to inhibit remodeling is similar to Psc and mPCC. (B) Activity of M33 domain deletions. (C) Activity of M33 carboxy-terminal truncations. $(D)$ Activity of M33 amino-terminal truncations.

To further investigate the observed activity of M33/ $\mathrm{Cbx} 2$, we performed a structure/function analysis to determine what domain(s) of M33/Cbx2 are required for functional activity. Deletion of either the chromodomain or the C-box of M33/Cbx2 does not significantly decrease its activity (Fig. 1B,C). The chromodomain of $\mathrm{Cbx} / \mathrm{Pc}$ proteins is involved in targeting to chromatin (Fischle et al. 2003), and the C-box is required for repression activity in transfection assays (Schoorlemmer et al. 1997) as well as forming interactions with other PRC1 components (Satijn et al. 1997). Targeting is not anticipated to be necessary in vitro because association with the template is driven by mass action; thus, the lack of requirement for the chromodomain was not surprising. The lack of requirement for the C-box in vitro indicates that this domain might function primarily by directing interactions with other PcG proteins and thus may not be necessary for function of the isolated protein.

We next decided to create a series of truncation mutants to map where the repression activity was located. Progressive deletion into the core of $\mathrm{M} 33 / \mathrm{Cbx} 2$ from either end of the protein results in increasing loss of in vitro activity (Fig. 1C,D). This observation is reminiscent of what was seen for Psc: Functional activity spreads throughout the extended carboxyl terminus of Psc, with further truncation of the carboxyl terminus correlating with loss of both in vitro and in vivo activity. This is consistent with the idea that there is no well-defined repression domain but, rather, that repression activity is spread throughout the carboxyl terminus of the protein.

Through examination of the $\mathrm{M} 33 / \mathrm{Cbx} 2$ sequence, we observed what appears to be an overrepresentation of two basic amino acids, lysine and arginine. This abundance of basic amino acids is similar to what is found in the carboxyl terminus of Psc. We hypothesized that one of the repressive activities of the PcG proteins is mediated by a region of a PRC1 subunit with a high overall positive charge. We imagined that a localized region of high positive charge could potentially interact with nucleosomal DNA and mediate the compaction of chromatin, and block transcriptional activators from having access to their cognate sequences.

If this hypothesis were true, we would expect there to be a correlation between the charge of a given M33/Cbx2 mutant and resulting in vitro activity. In fact, if we plot the charge of a given $\mathrm{M} 33 / \mathrm{Cbx} 2$ mutant versus the concentration required for $50 \%$ inhibition of remodeling $\left(\mathrm{IC}_{50}\right)$, we see a significant correlation (Fig. 2). This result is consistent with the idea that charge is an important determinant of PRC1 activity. 
A

\begin{tabular}{|llll|}
\hline \multicolumn{5}{c}{$\begin{array}{l}\text { Observed IC } \\
\text { predicted }\end{array}$ and } \\
pharge values \\
\hline Protein & Size & IC50 & Charge \\
\hline M33 & 55 & 1.4 & 31.6 \\
\hline M33; $1-488$ & 51 & 1.8 & 31.3 \\
\hline M33; $1-394$ & 42 & 1.4 & 33.1 \\
\hline M33;1-329 & 35 & 3 & 32 \\
\hline M33;1-258 & 28 & $26 *$ & 24.8 \\
\hline M33;1-179 & 20 & $60 *$ & 18.5 \\
\hline M33;62-519 & 48 & 3.5 & 29.5 \\
\hline
\end{tabular}

B

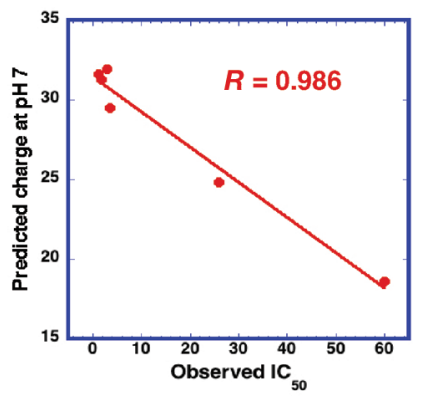

Figure 2. Correlation of M33 repression activity and charge. (A) Table lists charge and observed activity of $\mathrm{M} 33 / \mathrm{Cbx} 2$ mutants. "Size" column is in kilodaltons. Charge was estimated at $\mathrm{pH} 7.0$ using lasergene software. (Asterisks) $\mathrm{IC}_{50}$ was inferred by extrapolating curve fits. $(B)$ Plot of predicted charge at $\mathrm{pH}$ 7 and observed $\mathrm{IC}_{50}$ for inhibition of remodeling.

\section{Evolutionary Divergence of PRC1 Function}

Interestingly, the above analysis suggests that a different subunit of mouse core PRC1 has coopted the activity of Psc from the Drosophila core complex. Bmi1, the mouse homolog of Psc, is inactive in our in vitro assay. This is in contrast to $\mathrm{M} 33 / \mathrm{Cbx} 2$, a mouse homolog of $\mathrm{Pc}$, which is active. These observations could be explained in an evolutionary context by either coevolution of this particular PcG activity or by gain of this activity by one subunit followed by loss in another. Regardless of what actually occurred evolutionarily, both of these models suggest that organisms evolutionarily close to Drosophila are expected to have Psc homologs with high overall positive charge. Likewise, we expect organisms evolutionarily closer to mouse to have Pc homologs with high overall positive charge. To test this hypothesis, we examined divergent homologs of Psc and Pc in multiple species and analyzed the charge characteristics of each protein.

To accomplish this in an unbiased manner, we used a computational approach to "call" PcG proteins and classify them as active or inactive based on charge. To call Pc (or M33) homologs, we queried the SWISS-PROT database for proteins containing a chromodomain and a C-box motif, the hallmarks of this class of $\mathrm{PcG}$ protein. To find Psc homologs, the database was queried using the conserved RING domain plus the extended homology domain of Psc. This method yielded 44 M33/Cbx2 homologs and 59 Psc homologs. Although we cannot exclude the possibility that putative PcG proteins were missed, the proteins that were called should be representative and are likely to contain the majority of homologs in the database. Notably, many proteins that were called have GO classifications of PcG proteins, and one protein, Caenorhabditis elegans Mig-32, has recently been shown to be a functional Psc homolog in the worm (Karakuzu et al. 2009).

To classify the proteins as either active or inactive, we used the predicted charge at $\mathrm{pH} 7$ and set a threshold of +10.2 for candidate homologs to be categorized as inactive. This cutoff was defined based on results with tested PcG proteins as described above. Even though we expect the activity to fall along a range, dependent on the charge level, this binary system makes testing the predictions simpler. Using this criterion, we find that 32 of 44 $\mathrm{M} 33 / \mathrm{Cbx} 2$ homologs are predicted to be "active" in our assay. In contrast, 55 of 59 Psc homologs are predicted to be "inactive."

To further understand these results in the context of evolution, we generated a cladogram using an alignment of the $18 \mathrm{~S}$ rRNAs from each of the species in which we found putative PcG proteins (Fig. 3). There is a clear dichotomy: Organisms more closely related to Drosophila have Psc homologs that are predicted to be active, whereas the organisms more closely related to mouse have Pc (M33/ Cbx2) homologs that are predicted to be active. Of note is that despite the high number of Psc homologs in mammals, none was classified as active. These results support the hypothesis that during evolution this particular activity of PRC1 was "swapped" among different subunits.

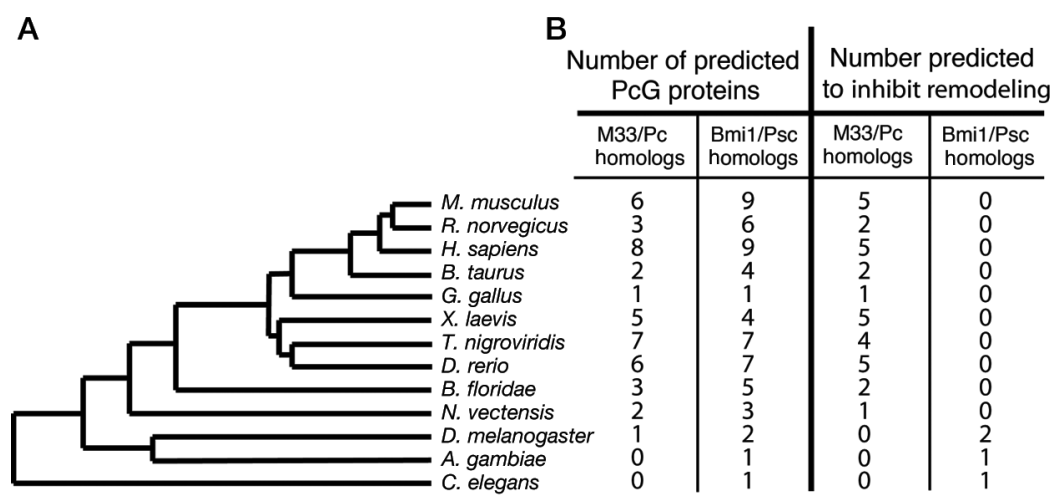

Figure 3. Predicted repression activity of evolutionary PcG homologs. (A) Cladogram of species generated by alignment of $18 \mathrm{~S}$ ribosomal RNA sequences. $(B)$ Number of predicted PcG proteins from each species and number of proteins over the charge threshold of +10.2 . 


\section{Interaction of the Zeste Protein with PRC1 in Drosophila}

The targeting of Polycomb-group proteins and the activity at loci distant from the nucleation sites are fundamental issues in the mechanism of PcG silencing. Simple models of sequential action by PRC2, which methylates K27 on histone H3, and PRC1, which binds the K27 mark via the Pc chromodomain, are not sufficient to explain PRC1 recruitment. The affinity of the chromodomain of Pc for trimethylated lysine 27 on histone $\mathrm{H} 3$ is low (Fischle et al. 2003), and certain Pc homologs do not display a strong preference for K27 methylation over K9 methylation (Bernstein et al. 2006). Histone marks might confer an extra level of stability to the binding of PRC1, which is important, but histone methylation is unlikely to be the sole mechanism of targeting.

Studies using Drosophila have identified a multitude of DNA-binding proteins that recognize PREs and are proposed to recruit PcG complexes via direct interaction. One such factor, Zeste (Fig. 4A), was identified as an integral component of the PRC1 complex as isolated from Drosophila embryos (Saurin et al. 2001), which suggested a mechanism for directly targeting the complex to chromatin. Interestingly, Zeste, which is a transcriptional activator for the Ubx gene (Biggin et al. 1988), has been classified as a Trithorax-group protein and shown to interact physically with several Brahma-associated factors (BAFs) in the Brahma complex (Kal et al. 2000). Such dualism is confirmed by the fact that Zeste is required for the maintenance of both active (Déjardin and Cavalli 2004) and repressed (Hur et al. 2002) states of transcription, in both cases, an activity that depends on TrxG/PcG function.

To characterize how the Zeste protein interacts with PRC1, we used a reconstitution approach to define the binding interaction and to determine whether we could measure a functional outcome of that interaction. We coinfected $S f 9$ cells with baculovirus for the four core PRC1 factors, or these factors plus Zeste, and purified the PCC and PCCZ complexes, respectively, through the Flag tag on the subunit $\mathrm{Ph}$. We were able to generate complexes with stoichiometric levels of Zeste protein, indicating that

A
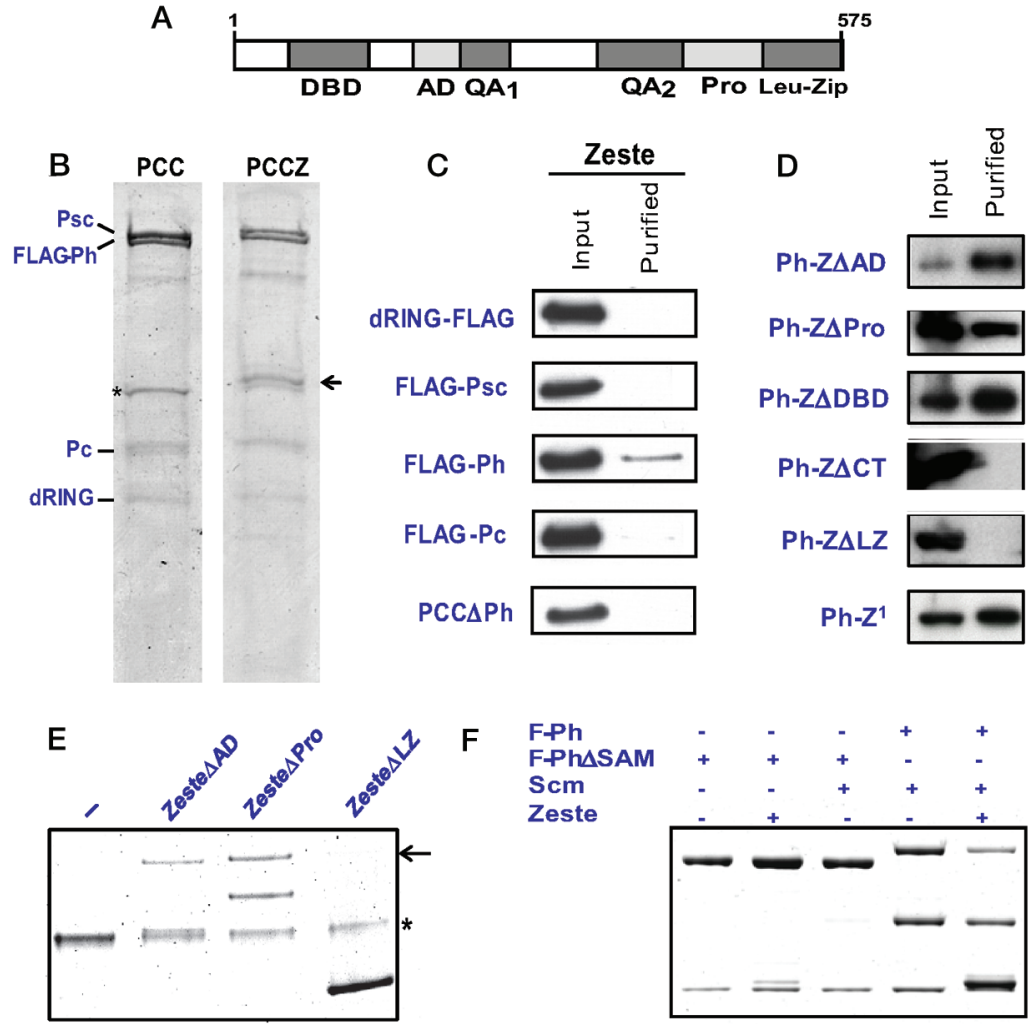

$F$

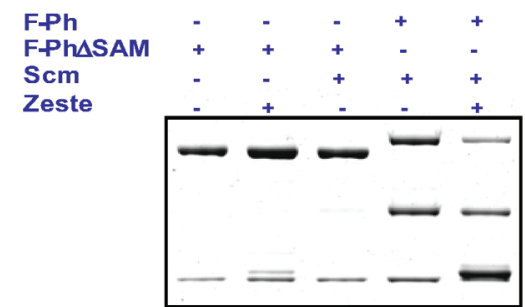

Figure 4. The interaction of Zeste with Polyhomeotic. (A) The domain structure of the Zeste protein. (DBD) DNA-binding domain, (AD) activation domain, (QA) glutamine/alanine-rich domain, (Pro) proline-rich domain, (Leu-Zip) leucine zipper. $(B)$ Purification of recombinant PCC and PCC-Zeste from Baculovirus-infected Sf9 cells. (Arrow) Zeste, (asterisk) contaminating band. (C) Western blot for Zeste, for input and protein purified through the Flag tag on the indicated protein, coinfected with Zeste. PCC $\triangle \mathrm{Ph}$ is a coinfection with FLAG-Psc, dRING, Pc, and Zeste. $(D)$ FLAG-PH was coinfected with the indicated mutants of Zeste and purified through the Flag tag. Western blot for input and purified protein for Zeste. $\left(\mathrm{Z}^{1}\right) \mathrm{K} 425 \mathrm{M}$ point mutant, $(\mathrm{Z} \Delta \mathrm{CT})$ carboxy-terminal truncation that eliminates the proline-rich and leucine-zipper domains. $(E)$ Full-length HA-tagged Zeste was coinfected with a Flag-tagged version of the indicated truncation mutants, and protein that was purified through the Flag tag was detected by Colloidal Blue staining. (Arrow) Full-length Zeste, (asterisk) nonspecific protein, (- lane [above, left]) infection with full-length Zeste alone. $(F)$ Colloidal Blue staining of protein purified through the Flag tag of $\mathrm{PH}$, in the combinations indicated. Zeste is the thicker band just above the nonspecific protein found on all purifications. 
Zeste associates strongly with the core PRC1 (Fig. 4B). We then asked whether this interaction is mediated by a direct physical contact with one of the core factors. To this end, we coinfected $S f 9$ cells with baculovirus for Zeste and a Flag-tagged version of each of the PCC proteins. We then purified the Flag-tagged protein and identified Zeste in the eluates by western blot. $\mathrm{Ph}$ is both sufficient and necessary for the association of Zeste with PCC, because $\mathrm{Ph}$ alone bound to Zeste and a partial PCC complex lacking $\mathrm{Ph}$ (PCC $\triangle \mathrm{Ph}$ ) was unable to interact with Zeste (Fig. 4C).

Having defined $\mathrm{Ph}$ as the interacting protein, we used the same strategy described above to characterize the domains required for interaction between $\mathrm{Ph}$ and Zeste. We made several deletion mutants of Zeste for use in interaction studies. Mutants lacking the activation domain, proline-rich domain, DNA-binding domain, or a K425M mutant (the $z^{l}$ mutant, which displays a neomorphic phenotype in flies) were all able to interact with FLAG-Ph (Fig. 4D). In contrast, mutants that lack the carboxyl terminus (proline-rich and leucine-zipper domains) or that lack the leucine zipper only, do not copurify with FLAG-Ph.

The leucine-zipper domain of Zeste has previously been found to be involved in a physical interaction with Moira, a subunit of the TrxG Brahma complex (Kal et al. 2000). Additionally, it has been implicated in aggregation of the Zeste protein, which has been suggested to have a role in the in vivo function of Zeste (Chen and Pirrotta 1993). Consistent with this observation, a mutant lacking the leucine zipper was shown to be deficient in self-association (Fig. 4E). We tested self-association by coinfecting $S f 9$ cells with full-length HA-tagged Zeste and a Flag-tagged version of a Zeste mutant that lacked one of either the activation, the proline-rich, or the leucine-zipper domains. Protein purified over an M2 Flag affinity column was separated by PAGE and stained with Colloidal Blue. The leucine-zipper mutant is unable to recruit full-length Zeste, indicating that this domain is necessary for self-interaction.

We next were interested in testing whether a known interaction module in $\mathrm{Ph}$, the SAM domain, mediates the interaction with Zeste. We coinfected $S f 9$ cells with FLAG-Ph or FLAG-Ph $\triangle \mathrm{SAM}$ and Zeste. As a positive control, we used Sex Comb on the Midleg (Scm), a PcG protein known to interact with the SAM domain of Ph. As expected, we could see a SAM-dependent interaction between $\mathrm{Ph}$ and $\mathrm{Scm}$ (Fig. 4F). Furthermore, the $\mathrm{Ph} \Delta \mathrm{SAM}$ mutant had a much lower affinity for Zeste, suggesting that the SAM domain is a common docking site for both $\mathrm{Scm}$ and Zeste. Binding to $\mathrm{Ph}$ is possibly done using different surfaces of the SAM domain, because both Scm and Zeste can copurify with $\mathrm{Ph}$ simultaneously.

We wished to determine whether the interaction between $\mathrm{Ph}$ and Zeste has a measurable impact on activity of either Ph alone or the core PRC1 complex. To perform these studies, we first determined the function of $\mathrm{Ph}$ alone. As discussed above, the inhibitory activity of PRC1 on chromatin appears to be due to the high positive charge of the complex, a characteristic that is unique to PRC1 among the known fly PcG complexes (Fig. 5A). Interestingly, a different complex that includes Psc, the dRAF complex (Lagarou et al. 2008), is not known to have a di-
A

\begin{tabular}{|lr|lr|}
\hline \multicolumn{2}{|c|}{ Drosophila PRC1 } & \multicolumn{2}{c|}{ Mouse PRC1 } \\
\hline Protein & Charge & Protein & Charge \\
\hline Posterior sex combs & 82.1 & BMI1 & 2.2 \\
Polyhomeotic & 25.8 & RAE-28 & 18.3 \\
Polycomb & 4.2 & M33 & 32.5 \\
dRING & 0.6 & RING1B & -1.1 \\
& & & \\
dPCC & $\mathbf{1 1 2 . 7}$ & mPCC \\
\hline Zeste & \multicolumn{2}{|c|}{} \\
PRC2 & -2.7 \\
PhoRC & -17 \\
dRAF & -31.2 & \\
\hline
\end{tabular}
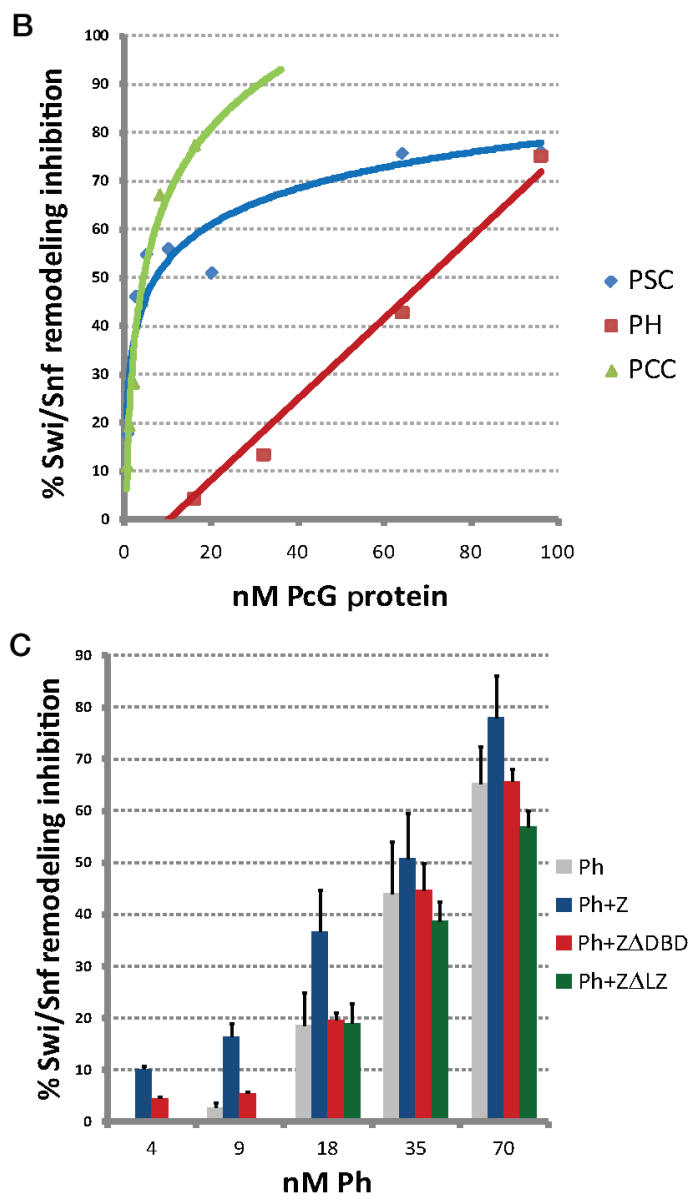

Figure 5. Functional analysis of Polyhomeotic and Zeste. $(A)$ Charge of the PRC1 core complex proteins from Drosophila and mouse and of other Drosophila PcG complexes and Zeste. $(B)$ Swi/Snf remodeling inhibition by dPCC, Psc, and Ph. (C) Interaction of wild-type and mutant Zeste with $\mathrm{Ph}$ in Swi/Snf.

rect impact on chromatin remodeling activity and bears an overall charge of -17.3 . This suggests that other factors in PRC1 contribute to the overall charge and, therefore, activity. Ph, although not as positively charged as Psc, bears a net charge above the threshold that was used for calling a PcG protein as potentially active in the inhibition of remodeling. Likewise, a $\mathrm{Ph}$ homolog in mouse, RAE28 , also has an intermediate positive charge.

To determine whether the predicted charge of these proteins was indicative of biochemical activity, we measured 
the ability of purified recombinant PCC, Psc, and Ph to inhibit remodeling with the REA assay. As expected, PCC has the strongest inhibitory activity, closely followed by Psc (Fig. 5B). Ph displayed measurable inhibitory activity, albeit only at higher concentrations than PCC or Psc.

Zeste has previously been shown to have an impact on the activity of PCC (Mulholland et al. 2003). Given the physical interaction between Zeste and Ph (Fig. 4), Zeste might directly enhance the activity of $\mathrm{Ph}$. To test this hypothesis, we again used the REA assay. By preincubation of the nucleosomal arrays with either $\mathrm{Ph}$ alone or $\mathrm{Ph}$ plus wild-type or mutant versions of Zeste, we could determine whether Zeste enhances the activity of Ph (Fig. 5C). The inclusion of Zeste in the preincubation has a measurable, but modest, effect on the activity of $\mathrm{Ph}$, more prominent at lower concentrations. Removal of either the DNA-binding domain $(\mathrm{Z} \triangle \mathrm{DBD})$ or the leucine-zipper domain $(\mathrm{Z} \Delta \mathrm{LZ})$ abrogated the stimulatory effect of Zeste. These results suggest that the interaction of Zeste with $\mathrm{Ph}$ stimulates the inhibitory activity of $\mathrm{Ph}$, dependent on both the DNA-binding domain and the leucine-zipper domain of Zeste. This dependence might be due to either the reduced physical interaction of the $\mathrm{Z} \Delta \mathrm{LZ}$ mutant with $\mathrm{Ph}$ or to the inability of this mutant to oligomerize. The effect of Zeste on $\mathrm{Ph}$ is unlikely to be related to charge because Zeste has a net negative charge.

\section{DISCUSSION}

We have examined the biochemically active regions of two key components of PRC1 and have generated the hypothesis that the high net positive charge of these regions is important for the ability of PRC1 to compact chromatin. Surprisingly, the region enriched for basic amino acids, which was originally identified in the Drosophila Psc protein, appears to have swapped location to the mouse Pc homolog at some time during the evolutionary process. Although these regions do not show significant sequence alignment when the relevant PcG proteins are compared, it does appear that the overall amino acid content has been maintained. Every organism we examined contains at least one component of PRC1 that has the characteristic high positive charge. An important test of the hypothesis that this charge distribution is central to compaction will involve testing the extent of compaction produced by the various PRC1 proteins from different species.

The role of PRC1 in compacting chromatin in vitro has been well established by our previous work, and the ability of Drosophila Psc to compact chromatin in vitro has been correlated with its ability to repress homeotic genes in vivo (King et al. 2005). More recent studies support the hypothesis that compaction is a key function of the PcG system and that PRC1 is a central player in this activity. A study of nucleosome turnover revealed slower rates of turnover on genes repressed by the PcG system than on genes bound by Trithorax-group protein, consistent with a more inaccessible state (Deal et al. 2010). A study that looked at compaction at the cytological level showed that the HOX clusters in mouse are compacted when repressed and that compaction is dependent on PRC1, but not on the ubiquitylation function of PRC1 (Eskeland et al. 2010). This result separates the compaction and enzymatic functions of PRC1 and suggests that compaction has the primary role in the repression of HOX. The compaction observed in these studies in mice, measured cytologically, might be caused by the same PRC1 function that represses remodeling and creates compacted structures visible by electron microscopy. It is important to recognize that these two events have not yet been equated mechanistically.

The swapping of the compaction domain between Psc and Pc homologs has important ramifications for the interplay between histone $\mathrm{H} 2 \mathrm{~A}$ ubiquitylation and compaction. The ubiquitylation activity requires a Psc homolog and a RING homolog. There are at least two distinct PRC1 family complexes that contain both Psc and RING homologs in Drosophila and mammals. The originally defined PRC1 complex contains Psc, Pc, Pc, and RING homologs, whereas the dRAF complex (Drosophila) and BCOR complex (mammals) contain Psc and RING homologs but are not known to contain Pc homologs. Interestingly, the inclusion of the highly positively charged Psc in the dRAF complex is accompanied by the presence of the highly negatively charged Mtor and Ulp1, with the whole complex having a net charge of -17.3 . These latter complexes in the PRC1 family are proficient at ubiquitylation and have been proposed to be the central ubiquitylating complexes in Drosophila and mammals. The swap of the compaction domain between Psc and Pc means that in mammals, the compaction activity is found in only one subset of the PRC1 complexes, whereas in Drosophila, this domain is found in both PRC1 and dRAF. In mammals and in most organisms listed in our evolutionary comparison, there is the potential to separate these two functions between complexes. One can imagine that inclusion or omission of certain PcG functions could fine-tune the level of either compaction or ubiquitylation at the various genes regulated by the PRC1 family of complexes.

We have also mapped the domains involved in the association of the Zeste protein with PRC1 in Drosophila but were unable to uncover a clear functional role for that interaction. The Zeste protein is of significant interest in the biology of PRC1 because it binds stoichiometrically to the complex, both during reconstitution and when PRC1 is isolated from embryos, and it has a rich history of involvement in gene regulation, as determined by genetic studies (Pirrotta 1991). It therefore seems a strong candidate to have an important role in regulating PRC1 function. The types of role(s) that it might have are perplexing, because the genetic studies implicate it in both activation and repression, and it does not display classic PcG phenotypes and, in fact, displays some of the opposing Trithorax-group phenotypes.

Zeste interacts with $\mathrm{Ph}$, a PRC1 subunit that is involved in bridging interactions either involving self-association or association with proteins such as Scm. Zeste is also able to self-associate. It is possible, then, that Zeste might modulate higher-order interactions between PcG complexes and targets. We tested whether Zeste might be involved in regulating compaction on arrays, possibly stimulated by changes in association, but did not observe any striking effects when 
Zeste was either combined with $\mathrm{Ph}$ alone or mixed with a full PRC1 reconstituted complex. In both instances, Zeste increased the ability to repress remodeling, but the effects were of modest magnitude. Perhaps a simple possibility explains the interaction of Zeste with PRC1: Zeste has the ability to bind DNA with sequence specificity, and it might solely target the complex without affecting activity. Its intricate genetic functions, the involvement in trans-sensing and -acting phenomena like transvection, and its ability to interact with the Brahma complex, a Trithorax-group complex, indicate, on the other hand, that something more complex might be involved.

\section{ACKNOWLEDGMENTS}

We thank Brad Chapman for help with the phylogenetic analysis of PcG proteins and S.K. Bowman for critical reading of the manuscript. Funding for this work was provided by the National Institutes of Health (GM43901). J.M.A. was supported in part by a fellowship from Fundação para a Ciência e Tecnologia (SFRH/BD/11800/2003).

\section{REFERENCES}

Abmayr SM, Yao T, Parmely T, Workman JL. 2001. Preparation of nuclear and cytoplasmic extracts from mammalian cells. Wiley, New York.

Bernstein E, Duncan EM, Masui O, Gil J, Heard E, Allis CD. 2006. Mouse Polycomb proteins bind differentially to methylated histone $\mathrm{H} 3$ and RNA and are enriched in facultative heterochromatin. Mol Cell Biol 26: 2560-2569.

Biggin MD, Bickel S, Benson M, Pirrotta V, Tjian R. 1988. Zeste encodes a sequence-specific transcription factor that activates the Ultrabithorax promoter in vitro. Cell 53: 713-722.

Chen JD, Pirrotta V. 1993. Multimerization of the Drosophila zeste protein is required for efficient DNA binding. EMBO J 12: 2075-2083.

Czermin B, Melfi R, McCabe D, Seitz V, Imhof A, Pirrotta V. 2002. Drosophila enhancer of Zeste/ESC complexes have a histone H3 methyltransferase activity that marks chromosomal Polycomb sites. Cell 111: 185-196.

Deal RB, Henikoff JG, Henikoff S. 2010. Genome-wide kinetics of nucleosome turnover determined by metabolic labeling of histones. Science 328: 1161-1164.

Déjardin J, Cavalli G. 2004. Chromatin inheritance upon Zestemediated Brahma recruitment at a minimal cellular memory module. EMBO J 23: 857-868.

Eskeland R, Leeb M, Grimes GR, Kress C, Boyle S, Sproul D, Gilbert N, Fan Y, Skoultchi AI, Wutz A, Bickmore WA. 2010. Ring1B compacts chromatin structure and represses gene expression independent of histone ubiquitination. Mol Cell 38: 452-464.

Fischle W, Wang Y, Jacobs SA, Kim Y, Allis CD, Khorasanizadeh S. 2003. Molecular basis for the discrimination of repressive methyl-lysine marks in histone $\mathrm{H} 3$ by Polycomb and HP1 chromodomains. Genes Dev 17: 1870-1881.

Francis NJ, Saurin AJ, Shao Z, Kingston RE. 2001. Reconstitution of a functional core Polycomb repressive complex. Mol Cell 8: $545-556$

Francis NJ, Kingston RE, Woodcock CL. 2004. Chromatin compaction by a Polycomb group protein complex. Science 306: 1574-1577.

Gearhart MD, Corcoran CM, Wamstad JA, Bardwell VJ. 2006. Polycomb group and SCF ubiquitin ligases are found in a novel BCOR complex that is recruited to BCL6 targets. Mol Cell Biol 26: $6880-6889$.

Hur MW, Laney JD, Jeon SH, Ali J, Biggin MD. 2002. Zeste maintains repression of Ubx transgenes: Support for a new model of
Polycomb repression. Development 129: 1339-1343.

Judd BH. 1995. Mutations of zeste that mediate transvection are recessive enhancers of position-effect variegation in Drosophila melanogaster. Genetics 141: 245-253.

Kal AJ, Mahmoudi T, Zak NB, Verrijzer CP. 2000. The Drosophila brahma complex is an essential coactivator for the trithorax group protein Zeste. Genes Dev 14: 1058-1071.

Karakuzu O, Wang DP, Cameron S. 2009. MIG-32 and SPAT-3A are PRC1 homologs that control neuronal migration in Caenorhabditis elegans. Development 136: 943-953.

King IF, Emmons RB, Francis NJ, Wild B, Müller J, Kingston RE, Wu CT. 2005. Analysis of a Polycomb group protein defines regions that link repressive activity on nucleosomal templates to in vivo function. Mol Cell Biol 25: 6578-6591.

Klymenko T, Papp B, Fischle W, Köcher T, Schelder M, Fritsch C, Wild B, Wilm M, Müller J. 2006. A Polycomb group protein complex with sequence-specific DNA-binding and selective methyl-lysine-binding activities. Genes Dev 20: 1110-1122.

Kuzmichev A, Nishioka K, Erdjument-Bromage H, Tempst P, Reinberg D. 2002. Histone methyltransferase activity associated with a human multiprotein complex containing the Enhancer of Zeste protein. Genes Dev 16: 2893-2905.

Lagarou A, Mohd-Sarip A, Moshkin YM, Chalkley GE, Bezstarosti K, Demmers JA, Verrijzer CP. 2008. dKDM2 couples histone $\mathrm{H} 2 \mathrm{~A}$ ubiquitylation to histone $\mathrm{H} 3$ demethylation during Polycomb group silencing. Genes Dev 22: 2799-2810.

Lewis P. 1947. New mutants: Report of P. Lewis. Drosophila Inform Serv 21: 69.

Lewis EB. 1978. A gene complex controlling segmentation in Drosophila. Nature 276: 565-570.

Mulholland NM, King IF, Kingston RE. 2003. Regulation of Polycomb group complexes by the sequence-specific DNA binding proteins Zeste and GAGA. Genes Dev 17: 2741-2746.

Müller J, Hart CM, Francis NJ, Vargas ML, Sengupta A, Wild B, Miller EL, O'Connor MB, Kingston RE, Simon JA. 2002. Histone methyltransferase activity of a Drosophila Polycomb group repressor complex. Cell 111: 197-208.

Nakagawa T, Kajitani T, Togo S, Masuko N, Ohdan H, Hishikawa Y, Koji T, Matsuyama T, Ikura T, Muramatsu M, Ito T. 2008. Deubiquitylation of histone $\mathrm{H} 2 \mathrm{~A}$ activates transcriptional initiation via trans-histone cross-talk with $\mathrm{H} 3 \mathrm{~K} 4$ di- and trimethylation. Genes Dev 22: 37-49.

Phelan ML, Sif S, Narlikar GJ, Kingston RE. 1999. Reconstitution of a core chromatin remodeling complex from SWI/SNF subunits. Mol Cell 3: 247-253.

Pirrotta V. 1991. The genetics and molecular biology of zeste in Drosophila melanogaster. Adv Genet 29: 301-348.

Ringrose L, Paro R. 2007. Polycomb/Trithorax response elements and epigenetic memory of cell identity. Development 134: 223 232.

Rinn JL, Kertesz M, Wang JK, Squazzo SL, Xu X, Brugmann SA, Goodnough LH, Helms JA, Farnham PJ, Segal E, Chang HY. 2007. Functional demarcation of active and silent chromatin domains in human HOX loci by noncoding RNAs. Cell 129: 1311-1323.

Satijn DP, Gunster MJ, van der Vlag J, Hamer KM, Schul W, Alkema MJ, Saurin AJ, Freemont PS, van Driel R, Otte AP. 1997. RING1 is associated with the Polycomb group protein complex and acts as a transcriptional repressor. Mol Cell Biol 17: 4105-4113.

Saurin AJ, Shao Z, Erdjument-Bromage H, Tempst P, Kingston RE. 2001. A Drosophila Polycomb group complex includes Zeste and dTAFII proteins. Nature 412: 655-660.

Scheuermann JC, de Ayala Alonso AG, Oktaba K, Ly-Hartig N, McGinty RK, Fraterman S, Wilm M, Muir TW, Müller J. 2010. Histone H2A deubiquitinase activity of the Polycomb repressive complex PR-DUB. Nature 465: 243-247.

Schoorlemmer J, Marcos-Gutiérrez C, Were F, Martinez R, Garcia E, Satijn DP, Otte AP, Vidal M. 1997. Ring1A is a transcriptional repressor that interacts with the Polycomb-M33 protein and is expressed at rhombomere boundaries in the mouse hindbrain. EMBO J 16: 5930-5942.

Shao Z, Raible F, Mollaaghababa R, Guyon JR, Wu CT, Bender W, Kingston RE. 1999. Stabilization of chromatin structure by 


\section{GRAU ET AL.}

PRC1, a Polycomb complex. Cell 98: 37-46.

Sif S, Saurin AJ, Imbalzano AN, Kingston RE. 2001. Purification and characterization of $\mathrm{mSin} 3 \mathrm{~A}$-containing $\mathrm{Brg} 1$ and $\mathrm{hBrm}$ chromatin remodeling complexes. Genes Dev 15: 603-618.

Simon JA, Kingston RE. 2009. Mechanisms of Polycomb gene silencing: Knowns and unknowns. Nat Rev Mol Cell Biol 10: 697-708.
Stock JK, Giadrossi S, Casanova M, Brookes E, Vidal M, Koseki H, Brockdorff N, Fisher AG, Pombo A. 2007. Ring1-mediated ubiquitination of $\mathrm{H} 2 \mathrm{~A}$ restrains poised RNA polymerase II at bivalent genes in mouse ES cells. Nat Cell Biol 9: 1428-1435.

Zhao J, Sun BK, Erwin JA, Song JJ, Lee JT. 2008. Polycomb proteins targeted by a short repeat RNA to the mouse X chromosome. Science 322: 750-756. 


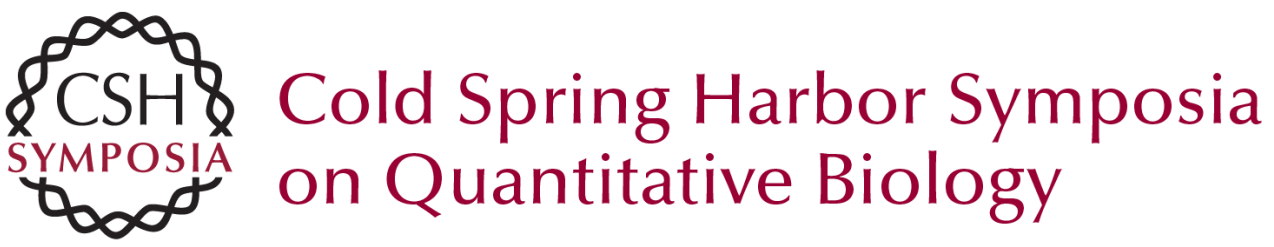

\section{Functional Dissection of Polycomb Repressive Complex 1 Reveals the Importance of a Charged Domain}

D.J. Grau, J.M. Antao and R.E. Kingston

Cold Spring Harb Symp Quant Biol 2010 75: 61-70 originally published online April 18, 2011 Access the most recent version at doi:10.1101/sqb.2010.75.056

References This article cites 37 articles, 18 of which can be accessed free at: http://symposium.cshlp.org/content/75/61.full.html\#ref-list-1

License

Email Alerting Receive free email alerts when new articles cite this article - sign up in Service the box at the top right corner of the article or click here. 